\title{
A sombra, o tirano e o louco: o dualismo Ocidente/Oriente no jornalismo visual ${ }^{1}$
}

//////////// Alberto Klein ${ }^{2}$

1. Trabalho apresentado ao Grupo de Trabalho Imagem e Imaginários Midiáticos do XXII Encontro Anual da Compós, na Universidade Federal da Bahia, Salvador, de 04 a 07 de junho de 2013.

2. Professor do Programa de Mestrado em Comunicação da Universidade Estadual de Londrina. Doutor em Comunicação e Semiótica pela Pontifícia Universidade Católica de São Paulo. Email: betoklein@yahoo. com.br. 
Resumo Este artigo explora o dualismo entre Ocidente e Oriente a partir de três imagens: a sombra, o tirano e o louco, respectivamente vinculadas às figuras de Osama Bin Laden, Saddam Hussein e Mahmoud Ahmadinejad. Tais representações, dada a sua constante reincidência, aparecem como estereótipos no jornalismo visual, estando diametralmente em oposição a valores ocidentais, como luz, democracia e razão. O texto também parte do conceito de Orientalismo para analisar procedimentos semióticos que constituem o processo de demonização dos referidos personagens, segundo as contribuições de Ivan Bystrina, Gilbert Durand e Stuart Clark.

Palavras-chave Oriente Médio, orientalismo, demonização.

Abstract This paper explores the East and West dualism considering three images: the shadow, the tyrant and the insane, respectively linked to Osama Bin Laden, Saddam Hussein and Mahmoud Ahmadinejad. These representations, given their occurrence in the media, appear as stereotypes in the visual journalism, being in total opposition to western values, such as illuminism, democracy and reason. From the perspective of the concept of Orientalism, the text also analyzes semiotic procedures which constitute the process of demonization, according to the contribuitions of Ivan Bystrina, Gilbert Durand and Stuart Clark.

Keywords Middle East, orientalism, demonization. 


\section{O Dualismo Ocidente/Oriente no Jornalismo Visual}

As imagens não valem pelas raízes libidinosas que escondem, mas pelas flores poéticas e míticas que revelam

Gilbert Durand

A imediata reconfiguração cultural e política que se deu após os atentados de 11 de setembro de 2001 reacendeu no plano imaginário uma série de textos ancorados no dualismo histórico Ocidente/Oriente. Ampliado pela imprensa, este dualismo, que havia sido investigado exemplarmente pelo ensaísta norte-americano e palestino Edward Said em seu livro Orientalismo, simplificaria ainda mais seus matizes chegando ao limite do maniqueísmo. As investidas militares norte-americanas passaram desde então a se colocar como um empreendimento civilizatório de ilustrados contra o obscurantismo oriental, civilizados contra selvagens, luz contra as trevas do Islã. Justificativa que seria empregada com ares oficiais pelos EUA para ocupar militarmente o Iraque depois da descoberta da ausência das armas de destruição em massa, atribuídas ao governo de Saddam Hussein.

Além de reabilitar no imaginário ocidental essas imagens, elevaram o tom do espetáculo maniqueísta, entre outros episódios, a publicação das charges de Maomé em 2005 por um jornal dinamarquês e o curta metragem norte-americano sobre o profeta Maomé de 2012. Curiosamente os dois casos representam problemas acerca da concepção do uso de imagens no âmbito da religião. 
3. Os termos Ocidente e Oriente não se referem estritamente a uma ordem geográfica, mas refere-se ao modo utilizado por Said para problematizar a constituição de um dualismo que historicamente opôs países árabes do Oriente Médio e da África e o universo de nações tradicionalmente cristãs da Europa e da América.
Este trabalho focaliza três personagens que se notabilizaram pela sua intensa visibilidade midiática depois dos atentados terroristas: Osama Bin Laden, Saddam Hussein e Mahmoud Ahmadinejad. A escolha destes personagens leva em conta apenas sua visibilidade na mídia, uma vez que não há claramente alinhamentos políticos que possam ser considerados entre eles. Osama Bin Laden, morto em 2011, foi líder da organização terrorista Al Qaeda, responsável pelos ataques de 2001. Saddam Hussein foi presidente do Iraque entre os anos de 1979 a 2003, condenado à forca em 2005. Já Mahmoud Ahmadinejad tornou-se presidente do Irã desde o ano de 2005, sob olhares desconfiados do Ocidente de que promoveria o desenvolvimento nuclear de seu país. Estes três líderes sofreram semelhantemente processo de demonização que se consolidou pouco a pouco no imaginário ocidental.

Assim, este artigo debruça-se, para retomar a expressão de Durand, sobre o estudo das raízes libidinosas da imagem nas representações de tais figuras na imprensa brasileira, especificamente a Folha de S. Paulo e Veja, tendo como objetivo central analisar o dualismo Ocidente e Oriente ${ }^{3}$, através do modo pelo qual os três personagens citados são demonizados no processo de composição editorial no jornalismo visual.

Assim, este estudo filia-se aos estudos iconológicos propostos por W. J. T. Mitchell. Segundo o iconologista americano, uma recente preocupação com o estatuto assumido pela imagem na sociedade contemporânea, denominada por ele pictorial turn, levou à configuração de um novo campo de estudos visuais que não se restringem tradicionalmente à história da arte, mas antes envolve o estudo da dinâmica da imagem midiática em seus diversos suportes nos mais diversos ambientes, ampliando uma cultura assentada e condicionada pela visualidade. Seguindo esta trilha, o artigo analisa formas expressivas que se configuram a partir do dualismo Ocidente/ Oriente, que regula as operações editoriais e imaginárias na imprensa no mundo pós 11 de setembro. Ajuda assim a demonstrar como o imaginário atua sobre a realidade como em um sistema, retomando uma ideia de Castoriadis (1997).

O estudo das figuras de Osama Bin Laden, Saddam Hussein e Mahmoud Ahamadinejad podem ser pensadas tanto pela autonomia discursiva presente em alguns casos quanto pelas relações que tecem 
com outros elementos textuais, como título, linha fina, chapéu e legenda. Imagens técnicas por excelência (FLUSSER, 2002), as fotografias, bem como todo seu arcabouço de instrumentos editoriais gravitando em torno dela, refletem aquilo que Flusser denomina como seu caráter simbólico, entendido aqui como falta de espelhamento da realidade. Dessa forma é relevante destacar que para representar algo, o fotojornalismo submete-se a uma série de regras historicamente e tecnicamente condicionadas a fim de estabelecer um compromisso com um determinado objeto visível, o que o torna antes de tudo um construto tecno-sócio-histórico. Portanto, no plano da comunicação de massas atualmente, o fotojornalismo define o real pelo visível, dando-nos a impressão de que o visível é o real e que para o invisível não haja realidade qualquer. Realidade, assim, confunde-se com visibilidade. Mais visíveis que quaisquer outros personagens do mundo islâmico, Bin Laden, Saddam e Ahmadinejad, constituem, sobretudo, imagens que se submeteriam a um discurso permeado por estereotipias, segundo recursos editoriais que lhes acompanham dando forma a modos de representação.

Além da proeminência da imagem na sociedade contemporânea e das figuras selecionadas para análise do processo de demonização na mídia, o texto investe-se na continuidade de um estudo ainda não esgotado, a saber, as reconfigurações de sentido nas representações do Oriente islâmico depois dos atentados terroristas de 11 de setembro de 2001. O processo de demonização de líderes perpetuaria dessa forma todo arcabouço de representações e imagens denominadas por Said como Orientalismo.

Nos projetos anteriores "imagens em Conflito" e "Imagem e Ideologia no Jornalismo: demarcações semióticas do Islã em Veja”, pode-se observar a associação desses personagens a estereotipias na imprensa, sendo, via de regra, vinculadas ao signo da ameaça islâmica, caos e terrorismo. Nestes casos, o predomínio de estereótipos implicava uma visão unívoca segundo as lentes do Orientalismo. De fato, terrorismo e obscurantismo podem estar presentes no Islã, mas não só estão presentes lá, assim como também não ocupam todo Islã, como faz crer a mídia ocidental. Semelhantemente o processo de demonização deve ser pensado, conforme propomos, como um mecanismo redutor de significação. Ignora tudo que é complexo para dar preferência ao que é mais facilmente assimilável em um jogo de alteridades. 
Este jogo se dá principalmente através de imagens no fotojornalismo contemporâneo. Dessa forma, os personagens que ora analisaremos serão tratados a partir de seu substrato imagético, dado que sua subsistência é antes de tudo midiática. Ao privilegiar os aspectos representacionais e imaginários das imagens dos personagens escolhidos, a pesquisa não desmerece sua dimensão política e social, uma vez que se situam em zonas de produção de sentido permeadas por posturas ideológicas e editoriais. A mídia torna-se um palco de disputas representacionais políticas e ideológicas, que mobilizam e condicionam a produção imaginária de um determinado grupo social, que, por sua vez, retroage no plano das representações e ações políticas, formando assim um sistema (CASTORIADIS, 1997). Aqui a noção de representação é tomada a partir de regras e condições sociais e culturais que incidem na visão diante da imagem. Segundo Griselda Pollock, "a representação deve ser entendida como uma relação social promulgada e realizada por meio de exigências específicas à visão, assim como modos igualmente específicos de organizar espaços imaginários e corpos para olhar" (apud. DOMÈNECH, p.243, 2011).

\section{À sombra de Bin Laden}

A representação aqui é circunstanciada pela presença de marcas ou estereotipias. No caso de Bin Laden, a imagem espectral decorre do mesmo modo de sua relação com o universo das cavernas, habitat das sombras. Vincula-se imaginariamente à escuridão e ao submundo, restringindo sua existência a uma existência espectral. Bin Laden, pela sua condição de fugitivo até à morte, não era uma pessoa fotografada pelas agências de notícias. Fazia aparições na TV em vídeos gravados, cuja própria característica pixelizada colaborava para a natureza de espectro a rondar e ameaçar esporadicamente o Ocidente com novos ataques (figura 1).

Assim, os textos imaginativos culturais ligados à sombra devem ser explorados ao debruçarmos sobre este personagem. Vale lembrar que até mesmo em sua morte, a ausência do corpo visível acabou dando lugar a uma imagem manipulada, claramente para cumprir um papel de dar aos olhos o que ver, mesmo que fosse uma sombra de uma imagem mortuária. A sombra neste sentido compõe a própria natureza da imagem, uma vez que o sentido do vocábulo latino 
imago evoca uma forte relação com a morte e, consequentemente, com o mundo da escuridão.

Se a relação entre luz e sombra neste sentido não pode ser desfeita, a concepção de um oriente a partir do olhar ocidental deve assumir na visão de Jung a sombra como um nível inconsciente do próprio eu. Nesta mesma perspectiva, Connie Zweig e Jeremiah Abrams afirmam:

A sombra pessoal contém, portanto, todos os tipos de potencialidades não-desenvolvidas e não-expressas. Ela é aquela parte do inconsciente que complementa o ego e representa as características que a personalidade consciente recusa-se a admitir e, portanto, negligencia, esquece e enterra... até redescobri-las em confrontos desagradáveis com os outros (1994, p.15).

Portanto, uma dimensão especular entre Ocidente e Oriente deveria ser contemplada. Bin Laden representaria o optimum de uma recusa do Ocidente: o binômio fanatismo e terrorismo, síntese perfeita do Oriente, encarna-se neste personagem. Ao mesmo tempo em que o Ocidente aponta o dedo para o Oriente fanático e terrorista, não permite expor ao nível da consciência suas ações obsessivas e violentas de um histórico imperialista. Neste sentido, não consegue reconhecer no Oriente sua própria sombra. Segundo James Hillman:

\footnotetext{
O inconsciente não pode ser consciente; a Lua tem seu lado escuro, o Sol se põe e não pode iluminar o mundo todo ao mesmo tempo, e mesmo Deus tem duas mãos. A atenção e o foco exigem que algumas coisas fiquem fora do campo visual, permaneçam no escuro. Não se pode olhar em duas direções ao mesmo tempo (apud. ZWEIG; JEREMIAH, 1994, p.17)
}

Bin Laden não subsiste senão pela sua natureza espectral. Suas aparições em vídeo demarcavam mais a sua própria invisibilidade pela condição de fugitivo. Refugiado em cavernas, suas imagens na mídia reiteravam mais do que nunca a condição ontológica da própria imagem: presença de uma ausência, ou ausência de uma presença. 
Entretanto, a questão central que se coloca em relação às representações de Bin Laden é de que maneira sua imagem espectral disseminada pelos meios de comunicação constitui-se sobremodo como uma imagem demonizada. Na revista Veja, este processo se dá claramente por mecanismos editoriais em que a utilização de cores tem um papel fundamental na composição de sentido. $\mathrm{O}$ ar pastoril (figura 2) - quase sempre segurando um cajado - da figura de Bin Laden deve ser contrastado com tons fortes de vermelho e preto, que dentro do campo editorial, em sua relação com títulos e legendas, tenta levar o leitor a apreensão de um sentido unidirecional, a despeito do caráter polissêmico das imagens. O mesmo procedimento de utilização do vermelho para inicial do texto e o preto como pano de fundo é utilizado também para matérias como Saddam Hussein (figura 3) O sentido das trevas é constantemente rememorado pelo preto, o que evoca a partir de um regime noturno do imaginário (DURAND, 2006), não só a ausência de luz, mas a escuridão como profundidade, alusão novamente à caverna, cujo vínculo sensorial não se dá pela visão, mas pelos ouvidos. A associação sensorial da audição com a caverna remeteria a um movimento de interiorização psíquica na visão de Durand, ainda que o regime de representações da caverna esteja aqui condicionado pela informação massiva do jornalismo.

Figura 1

\section{FOLHA DE S.PAULO}

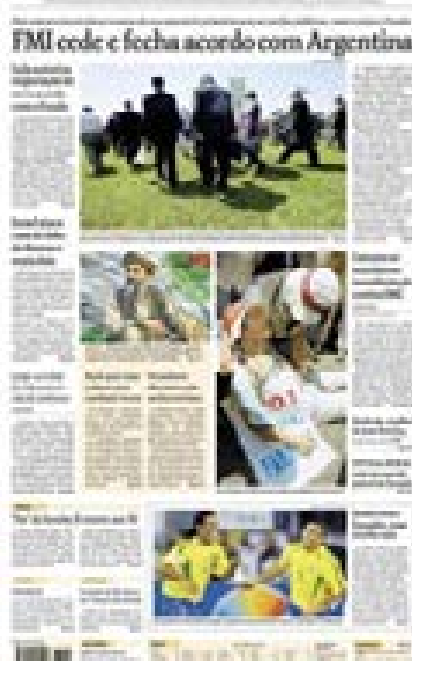

Figura 2

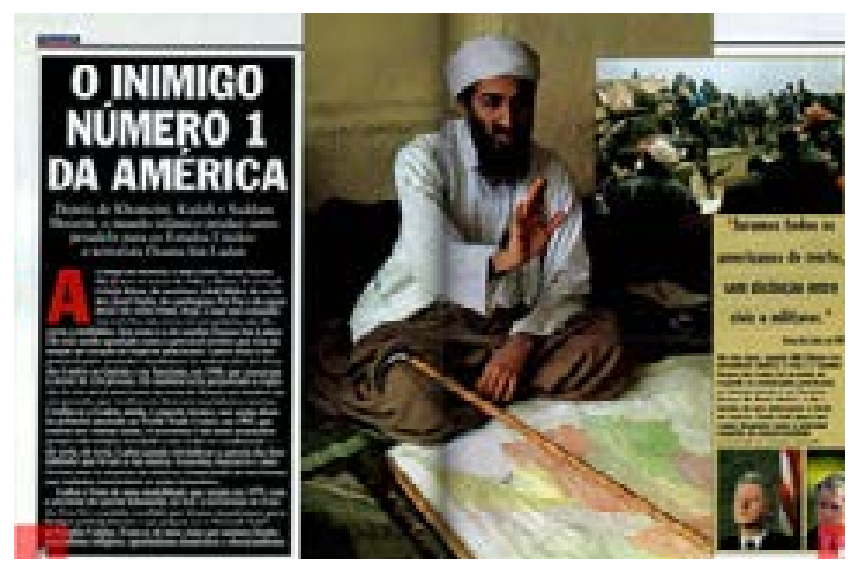




\section{Saddam: a destruição midiática do tirano}

A mesma indagação levanta-se em relação a Saddam Hussein, com frequência referido e chancelado pela imprensa como ditador e tirano. Saddam, já tinha sua imagem sedimentada na guerra do golfo, nos anos 90, quando invadiu o Kwait e provocou uma reação imediata dos países da OTAN. No decorrer da ação militar norteamericana no Iraque em 2003, o aspecto ameaçador da figura do déspota político é ressignificada na imprensa para a de opressor dentro de seu próprio país. Tal discurso viria ao encontro das pretensões norte-americanas de ocupação diante da inexistência de armas de destruição em massa.

A figura do tirano, cuidadosamente construída pela mídia ocidental (Saddam era sempre referenciado como ditador e não presidente) vem ao encontro do signo da ameaça. Somente um líder autoritário, megalomaníaco, soberbo, como dão conta suas representações visuais, poderia colocar-se como uma ameaça aos valores ocidentais. Aqui a noção de ameaça terrorista, que coaduna-se perfeitamente ao regime representacional da sombra em Bin Laden, é substituída pela ameaça política e bélica contra Israel, protetorado americano no Oriente Médio.

Outro aspecto representacional que chama a atenção nas primeiras observações é como os meios exploraram a vaidade e megalomania do líder iraquiano, tanto no plano político/religioso, autoconsiderado descendente do profeta Mohamed, quanto no plano das artes, como escritor de livros e peças teatrais. Traço característico da tirania, a vaidade mostra-se presente em várias poses fotográficas do líder iraquiano, ostentando charutos e ternos ocidentais, mesmo que tais representações já viessem da década de 80, época em que o Iraque era aliado político norte-americano (figura 3). 


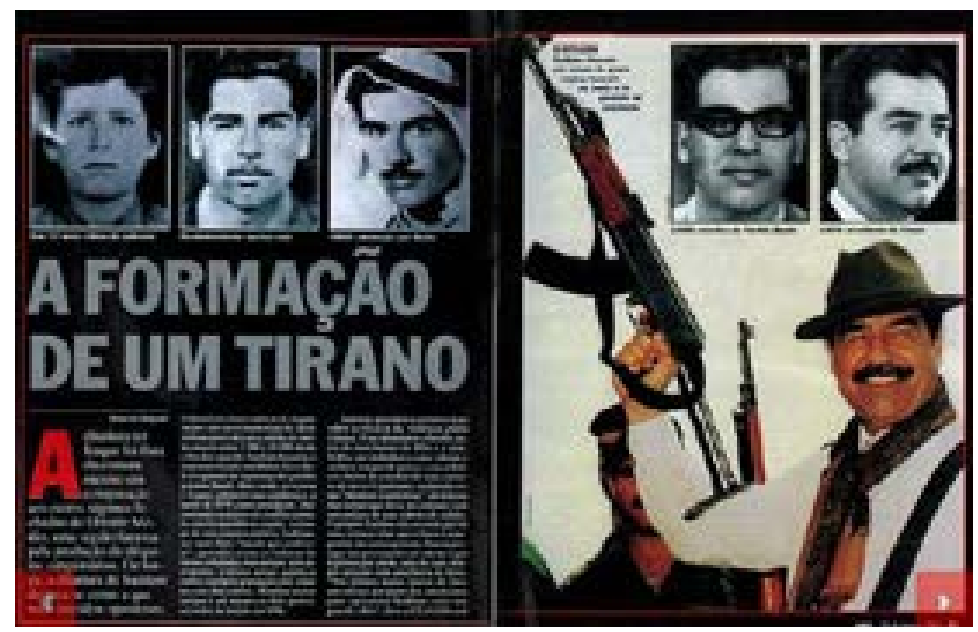

Figura 3

A exigência do culto à imagem, própria da vaidade - no âmbito das religiões abraâmicas, um principais traços demoníacos e motivo da queda de Lúcifer - iria exigir da mídia ocidental uma sequência de operações iconoclastas da imagem de Saddam Hussein. Primeiramente, a atenção midiática à queda de suas estátuas espalhadas pela cidade de Bagdá (figura 4). Em seguida, a captura do líder iraquiano em um buraco; sua exposição midiática usando roupas íntimas na prisão (fazendo clara referência a nudez do rei); e finalmente seu enforcamento gravado pela lente furtiva de um celular. Todos estes eventos possuem claramente uma natureza iconoclasta uma vez que tiveram a mídia como seu principal substrato.

A sequência iconoclasta de Saddam, sem dúvida, coloca-se como uma tentativa de exorcizar, na perspectiva americana, o maior ato

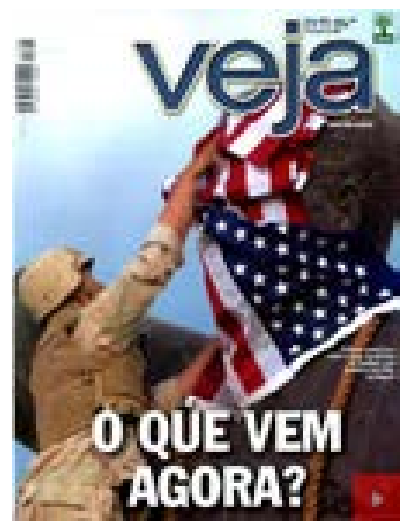

Figura 4 
iconoclasta depois da virada do milênio (o ataque às torres gêmeas). Ao tirano, levando em conta a carga simbólica de sua imagem, não restaria outra alternativa senão a sua destruição gradual diante das lentes ocidentais.

Todo ato iconoclasta configura-se a partir de uma visão dual de mundo. Neste universo, a principal condição para o ato de violência é a demonização da imagem do outro ante a sacralidade de nossas imagens. A necessidade de reforçar a tirania de Saddam Hussein converge com o desejo de destruir um inimigo possível, diante do desaparecimento de Bin Laden àquela época. Saddam, depois do 11 de setembro, passou a sintetizar um poder político cujos valores se opunham diametralmente aos valores políticos ocidentais. Sua imagem como tirano polarizava com a imagem de um Ocidente democrático.

Ao fazer uma tipologia do ato iconoclasta Bruno Latour aponta especialmente a violência contra imagens somente do inimigo e compara tal gesto a uma estratégia terrorista em que se tem o mínimo de investimento para o prejuízo máximo:

This is the well-known mechanism of provocation by which, in order to destroy someone as fast and as efficiently as possible, it is enough to attack what is most cherished, what has become the repository of all

4. Tradução do autor: Este é um conhecido mecanismo de provocação pelo qual, com o objetivo de destruir alguém tão rapidamente e eficientemente quanto possível, é suficiente atacar

o que lhe é mais caro, o que se tornou o repositório de todos os tesouros simbólicos de um povo (ver Lindhardt, Sloterdijk). Queima de bandeiras, destruição

de pinturas e sequestros são exemplos típicos. Diga-me o que

você considera mais querido

e eu destruirei de maneira a matá-lo mais rapidamente. É a estratégia mini-max característica das ameaças terroristas: o maior prejuízo com o mínimo de investimento. the symbolic treasures of one people (see Lindhardt, Sloterdijk). Flagburning, painting- slashing, hostage-taking are typical examples. Tell me what you hold to be most dear, and I will wreck it so as to kill you faster. It is the mini-max strategy so characteristic of terrorist threats: the maximum damage for the minimum investment (2000, p 28).

\section{Louco e Bobo}

Enfim, em Ahmadinejad a loucura parece ser um atributo sistematicamente associado à sua imagem. Mãos erguidas ou dedo em riste são detalhes imageticamente frequentes de uma figura sistematicamente apresentada na mídia, principalmente pela revista Veja, objeto de estudo em pesquisa anterior, sem equilíbrio. Cabe ainda observar como um jornal diário, com menor tempo para lançar mão de recursos editoriais, explorou ou não este sentido.

Ademais, há um tom jocoso nessas representações somando-se à ausência de racionalidade e equilíbrio. Na revista Veja isto fica claro com o título "Formiga atômica" e a fotografia de Ahmadinejad 
Artigos



Figura 5
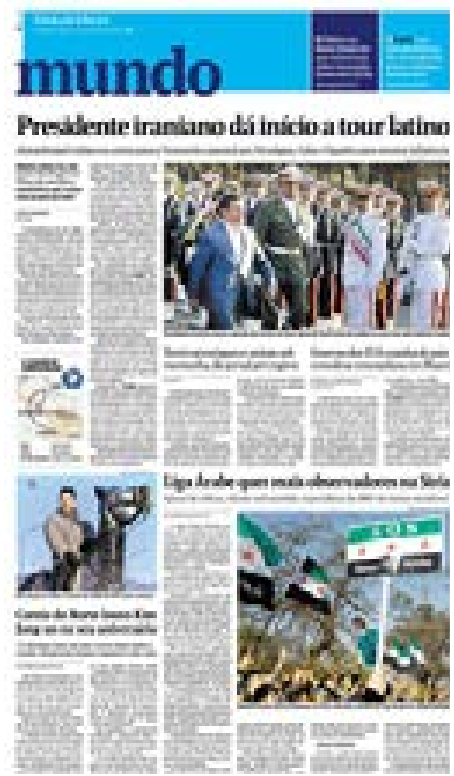

Figura 6

usando óculos especiais em uma instalação para testes nucleares. Outros títulos acompanham este, como uma série de apelidos: "o louco da bomba" (figura 5) ou "aiatolá atômico". Na Folha de S. Paulo este modo jocoso também aparece, principalmente por conta das viagens de Ahmadinejad pela América Latina a fim de angariar apoio político. Neste diário o empreendimento de Ahmadinejad foi denominado como "tour latino" (figura 6).

A associação entre Ahmadinejad, Evo Morales e Hugo Chaves em um tipo de discurso despolitizado, privilegiando na cobertura somente os aspectos pitorescos da visita, reforça, sobretudo, dois aspectos explorados pela imprensa: a demonização de Ahmadinejad por sua aproximação com líderes latino-americanos já demonizados pela imprensa brasileira e, por outro lado, o perigoso alinhamento de países como Bolívia e Venezuela com um país sobre o qual se levantam desconfianças de desenvolvimento de armas nucleares. A despolitização discursiva aparece em imagens que fazem da visita um encontro entre amigos íntimos e poderosos planejando suas próximas ações.

O tom jocoso das representações visuais de Ahmadinejad, expresso também verbalmente nas expressões "Formiga Atômica" ou "Tour latino" faz com que se aproximem o "louco" do "bobo". O antropólogo James Frazer admitia esta ligação. Segundo ele, o louco e o bobo preservavam a mesma condição em sacrifícios humanos 
como "vítimas de substituição" (apud. Cirlot, 1984), embora esta não seja necessariamente a condição de Ahmadinejad.

A ausência de equilíbrio é reiterada seja nos níveis da razão ou da inteligência. Tanto o louco quanto o bobo situam-se à margem das normas e do sistema e, portanto, circulam em uma zona de perigo em que as regras do mundo simplesmente não têm validade. A este respeito é notável a posição de Ivan Bystrina (1995) ao admitir a loucura como uma das raízes transformadoras da cultura. Por se colocarem fora do sistema de regras, pessoas que apresentam psicopatologias, ao perceberem o mundo de um modo diferente, podem antecipar futuros códigos da cultura. Entretanto, permanecem sempre sob o signo da ameaça.

O signo da loucura se estabelece como um par perfeito para o signo da ameaça. Daí o esforço de caracterizar Ahmadinejad como um louco, pois cairia para o Ocidente como uma justificativa perfeita para uma intervenção no Irã. Somente um louco poderia despejar mísseis atômicos em Israel e afrontar o Ocidente. Assim, a figura de Ahmadinejad reverbera aspectos do Homo demens, conceito de Edgar Morin (s/d) que explora a face escondida e reprimida do Homo sapiens, que revelaria um homem dado aos excessos e ao erro. Ahmadinejad, nesta perspectiva, seria uma projeção mesma do Ocidente, relutante em admitir sua própria face demens ante sua cara séria e equilibrada, atributos típicos do sapiens.

Seja qual for o aspecto explorado em cada figura pela mídia, a representação da ameaça por meio dos líderes parece ser sistematicamente caracterizada em imagens e textos que as acompanham, reforçando a ideia de Oriente como espelho invertido do Ocidente.

\section{Estereotipia e demonização}

O Orientalismo, expressão criada por Edward Said, tratase de um grande corpo de conhecimentos sobre o Oriente que se desenvolve e se cristaliza durante o período colonial inglês e francês, principalmente nos séculos XVIII e XIX. Entretanto, ao invés de promover perspectivas plurais, o Orientalismo acabou perpetuando certos estereótipos que ainda hoje são mobilizados pela imprensa ocidental, tais como atraso civilizatório, obscurantismo religioso, opressão de gênero, selvageria, violência, terror, entre outros. 
Em 2012, os bondes de São Francisco e o metrô de Nova York permitiram que uma blogueira sionista colasse nos vagões cartazes com a seguinte mensagem: "Em uma guerra entre civilizados e incivilizados, com qual lado você ficaria? Apoie Israel”. Os processos de estereotipia, como se vê no exemplo acima, não significam necessariamente a criação de mentiras acerca de uma cultura ou um indivíduo, conforme Homi Bhabha. Antes, demarcam uma espécie de redução de sentido ao ponto de imobilizá-lo. Assim, pode haver, como de fato há, opressão e obscurantismo no Islã, mas o problema é que a redução desta imagem esconde a complexidade multicultural, teológica e social do Islã.

$\mathrm{Na}$ imprensa, este reducionismo se dá principalmente pelo mecanismo de reiteração de imagens no processo editorial. Certos padrões de imagens são exaustivamente repetidos até se naturalizarem. Assim, passam a cumprir apenas a expectativa de olhares, que não se chocam mais com imagens de vitimização de mulheres e crianças, ações terroristas, ou a fúria selvagem das massas. Tal naturalização de imagens aproxima-se, neste sentido, do conceito de mitologia de Roland Barthes (2003).

O estudo da estereotipia vinculada a Bin Laden, Saddam Hussein e Mahmoud Ahmadinejad não implica, portanto, sua inocência, uma vez que ela pode não mentir. Contudo, os estereótipos são formas de esconder, cumprindo aquilo que Flusser (2002) denomina como função biombo da imagem.

Os estereótipos, assim, cumprem um papel negativo em um jogo que pode ser reduzido a pares de opostos na perspectiva ocidental: civilização/selvageria, liberdade/opressão, paz/violência. No caso dos personagens a serem estudados sombra/luz, tirania/democracia, loucura/racionalidade.

\section{Assimetria e Polarização}

Ademarcação de oposições, inerente a este processo de estereotipia, constitui-se como um dos principais fatores condicionantes das formas de organização da cultura e da sociedade de um modo geral, na visão do neoestruturalista Rodney Needham. Segundo ele, "as formas sociais são universalmente determinadas por um número restrito de fatores relacionais que expressam as alternativas e limitações lógicas" 
(apud. CLARK, p. 63). Embora a palavra "determinadas" sugira uma maneira categórica que pouco condiz com formas de se pensar a formação dos textos culturais, ela age de acordo, neste texto como filiação da tradição estruturalista do autor. Isto, de qualquer modo, não implica um desmerecimento de suas reflexões, uma vez que a dualidade se assenta de fato como uma das bases de constituição dos textos imaginativos e criativos. Comentando o pensamento de Needham, o historiador Stuart Clark afirma que:

\footnotetext{
Uma das razões que ainda são dadas para a extraordinária difusão de sistemas binários de pensamento e ação é que certas condições essenciais de existência da natureza humana (como luz e escuridão, macho e fêmea e vida e morte) apresentam-se fisicamente como pares para sistemas de significação que os transformam em opostos (2006, p.64).
}

Também as reflexões da Escola de Tartu-Moscou, que mantinha semelhantemente o estruturalismo como uma de suas bases epistemológicas, consideraram a estratégia dualista na dinâmica de relações entre cultura e o que denominavam como não-cultura. Segundo os semioticistas desta escola, cujo nome mais expressivo era Iuri Lotman, a história reproduzia de uma maneira inequívoca formas culturais e seus antitéticos respectivamente, de maneira que seus processos repousavam em transformar "pecadores" em "santos" ou "escuridão" em "luz". A noção de semiosfera, desenvolvida por Lotman posteriormente, parece contestar a fixidez de tais relações.

Mas o fato, entretanto, é que os choques podem se dar efetivamente no imaginário e na cultura como imagens em guerra, título do livro de Serge Gruzinski (2001), sobre a colonização das terras e do imaginário indígena no México pelos espanhóis. O trabalho de Gruzinski é essencial para compreender o mecanismo de demonização das imagens do outro, bem como a violência simbólica da assimilação imaginária das imagens cristãs ocidentais pelos mexicanos. A aculturação pelas imagens não se deu por decorrência da conquista política dos europeus, liderados por Fernão Cortês no início do Século XVI, mas foi a estratégia que moveu tal conquista. Isto acarretou necessariamente a atribuição das imagens mexicanas a demônios e fetiches e o subsequente processo de iconoclastia. 
A aniquilação parece colocar-se como único horizonte possível da demonização. Nesta mesma época, a Europa vivia embates teológicos provocados pela Reforma, entre eles o próprio estatuto da imagem religiosa, cuja resposta protestante mais eloquente foram os episódios iconoclastas nos cantões reformados.

A noção de choque na organização dos textos culturais está do mesmo modo pressuposta na semiótica da cultura de Ivan Bystrina. Segundo o autor, os textos da cultura se organizam conforme bases codificadoras, podendo elas serem binárias, ternárias, quaternárias, e assim por diante. Em convergência com Needham, Bystrina (1995) reitera que o modo de codificação binário é o mais básico e arcaico da cultura e, portanto, o mais comum.

A dinâmica dos textos binários implica um processo de polarização, atribuição de polos positivo e negativo, além de uma assimetrização, ou seja, dotar o polo negativo com mais força, de maneira que sua percepção na cultura pressuponha um maior impacto. Na polarização entre vida e morte, por exemplo, a morte desfrutaria de uma percepção mais aguda. A assimetria é atestada, entre outros fatores, pelo fato de que, segundo Durand (1997), as trevas não necessitam de luz para sua existência, mas a luz inversamente necessita das trevas. Isto levaria, no plano cultural e imaginário, à procura de determinados de padrões de solução para assimetria, a saber: inversão, identificação e eliminação.

A inversão refere-se à troca de polaridade negativa pela positiva. No exemplo específico da morte, ela deixa de ser entendida como o fim da vida e torna-se passagem para uma outra espécie de vida. No caso da identificação, a negatividade da morte é incorporada a uma visão necrofílica. Finalmente, a eliminação significaria a tentativa de eliminar a qualquer preço a morte como uma realidade humana, como através de técnicas para perpetuação da juventude.

Todo este movimento dos textos culturais, explicado por Bystrina, parece constituir-se de fato como o processo pelo qual se dá a demonização. Afinal, personagens demonizados pela mídia passam de algum modo pela atribuição de polaridade negativa; são também, conforme observação prévia, representados de forma assimétrica e, enfim, indicam a necessidade de um padrão de solução, que nos casos de demonização, parece ser a eliminação.

Isto estaria em acordo com a série iconoclasta de Saddam 
Hussein até sua morte, o assassinato de Bin Laden promovido pela CIA, além das ameaças norte-americanas para intervir militarmente no Irã. Dessa maneira, os mecanismos da demonização não só confirmariam, mas convergiriam com a dinâmica dos textos culturais em geral, replicando do mesmo modo este movimento com a atribuição de marcas ou estereótipos. Assim, as figuras da sombra, ou fantasma, do tirano e do louco cumprem a função de fixar o negativo por meio de marcas ou valores invertidos em relação ao Ocidente, que, por sua vez, orgulha-se por valores como o esclarecimento, a democracia e racionalidade.

Fica também evidente que a atribuição da polaridade negativa desencadeia a necessidade de operações semióticas a fim de controlála. Demonizar significa assim dar condições e limites precisos da representação de um determinado texto da cultura, de modo a demarcar precisamente as bordas entre o positivo e o negativo. O mal sempre deve aparecer midiaticamente segundo normas e preceitos que lhe são impostos. Segundo Gilbert Durand, "figurar um mal, representar um perigo, simbolizar uma angústia é já, através do assenhoramento pelo cogito, dominá-los" (2002, p. 123). Os movimentos entre os textos culturais demonstram, via de regra, este controle pela assimilação constante do caos pelo cosmos na cultura. Segundo os semioticistas da Escola de Tártu-Moscou, esta assimilação também se evidenciaria pela relação dinâmica entre as esferas da cultura e não-cultura.

Ao situar o Oriente como negativo, o Ocidente da mesma maneira lançaria mão de uma estratégia de controle. Conforme Said, a própria noção de Oriente é um conceito ocidental, configurando desde sua formação um mecanismo de controle. Dessa maneira, demonizar significa também exercer uma espécie de domínio semiótico, pois permite saber de antemão e com clareza as fronteiras entre o positivo e o negativo, possibilitando antever uma série de operações para a resolução da binariedade. Aqui fica evidente a inversão do processo de assimetrização de polos, com a sobreposição do positivo sobre o negativo. Em decorrência da percepção mais forte do negativo no imaginário e na cultura, tais dispositivos de controle inverteriam o peso a favor do positivo.

Em seu livro "Pensando com Demônios", Clark descreve, a respeito da bruxaria na Europa moderna, como se efetiva esta 
espécie de controle, não somente pela constituição do dualismo, mas pelo próprio rito político e religioso de aniquilação de bruxas que este dualismo acarretou. Acreditava-se que o próprio juiz investia-se de um poder religioso e sobrenatural que o tornava imune diante da condenação de uma bruxa. Nesta mesma linha, a respeito do discurso colonialista, Bhabha afirma:

0 objetivo do discurso colonial é apresentar o colonizado como uma população de tipos degenerados com base na origem racial de modo a justificar a conquista e estabelecer sistemas de administração e instrução (1998, p. 111).

Assim os padrões de solução da polaridade, descritos por Bystrina, constituem-se, sobretudo, como estratégias de controle fornecidas pelo sistema da cultura. São formas de superação simbólica do negativo, que se efetivam e justificam ações políticas de neutralização ou aniquilação da alteridade.

A própria dinâmica do processo de demonização midiática não foi suficientemente esclarecida. Se os mecanismos descritos por Bystrina acerca da codificação dos textos da cultura, como pensar tais mecanismos na lógica da produção da informação para o mercado, levando também em conta os aditamentos da sociedade do espetáculo para o consumo de imagens? O espetáculo no jornalismo, neste sentido, levanta questões novas e instigantes às quais as reflexões em torno do dualismo não se ausentarão. 


\section{Referências}

BARTHES, Roland. Mitologias. Rio de Janeiro: Difel, 2003.

BHABHA, Homi. O local da cultura. Belo Horizonte: Ed. UFMG, 1998.

BYSTRINA, Ivan. Tópicos de semiótica da cultura. São Paulo: CISC, 1995.

CASTORIADIS, Cornelius. World in fragments. Stanford: Stanford University Press, 1997.

CIRLOT, Juan Eduardo. Dicionário de símbolos. São Paulo: Ed Moraes, 1984.

CLARK, Stuart. Pensando com demônios. São Paulo: Edusp,

DOMÈNECH, Josep Maria Catalá. A forma do real. São Paulo: Summus, 2011.

DURAND, Gilbert. As estruturas antropológicas do imaginário. São Paulo: Martins Fontes, 2002.

FLUSSER, Vilém. Filosofia da caixa preta. Rio de Janeiro: Relume Dumará, 2002.

GRUZINSKI, Serge. Images at war. Durham and London: Duke University Press, 2001.

LATOUR, Bruno; WEIBEL, Peter. Iconoclash. Cambridge: MIT Press, 2002.

MACHADO, Irene. Escola de semiótica: a experiência de TártuMoscou para o estudo da cultura. Cotia: Ateliê Editorial, 2003.

MITCHELL, W.J.T. Iconology: image, text, ideology. Chicago: The University of Chicago Press, 1986. 
MORIN, Edgar. O paradigma perdido. Lisboa: EuropaAmérica, s/d.

SAID, Edward. Orientalismo: o Oriente como invenção do Ocidente. São Paulo: Companhia das Letras, 2007.

ZWEIG, Connie; ABRAMS, Jeremiah (orgs). Ao encontro da sombra. São Paulo: Cultrix, 1994.

Artigo recebido em outubro de 2013 e aprovado em junho de 2014. 